\title{
Outcomes after lobar versus sublobar resection for clinical stage I non-small cell lung cancer in patients with interstitial lung disease
}

\author{
Yasuhiro Tsutani, MD, PhD, Takeshi Mimura, MD, PhD, Yuichiro Kai, MD, Masaoki Ito, MD, PhD, \\ Keizo Misumi, MD, PhD, Yoshihiro Miyata, MD, PhD, and Morihito Okada, MD, PhD
}

\begin{abstract}
Objective: Since the prognosis after standard lobectomy for non-small cell lung cancer (NSCLC) in patients with interstitial lung disease (ILD) is poor, we investigated the possibility of sublobar resection for the improvement of the surgical results in such patients.
\end{abstract}

Methods: Of 796 consecutive patients with clinical stage I NSCLC who underwent pulmonary resection, 107 were diagnosed with ILD using high-resolution computed tomography (HRCT). Overall survivals (OS) were compared between patients with non-ILD and those with ILD or between patients with ILD who underwent lobectomy and those who underwent sublobar resection. ILD patterns consisted of usual interstitial pneumonia (UIP), possible UIP, and inconsistent with UIP. The log-rank statistics and Cox proportional hazard models were used to test for survival differences.

Results: OS was significantly lower in patients with "ILD inconsistent with UIP" pattern (hazard ratio [HR], 2.66; 95\% confidence interval [CI], 1.19-5.97; $P=.014$ ), or "ILD with possible UIP or UIP" patterns (HR, 2.38; 95\% CI, $1.76-3.21 ; P<.001)$ compared with patients with non-ILD. No significant difference in OS was observed between patients with ILD who underwent either lobectomy or sublobar resection (HR, 1.82; 95\% CI, 0.81-4.06; $P=.19$ ). Multivariable Cox analysis demonstrated diffusing capacity of the lung for carbon monoxide (HR, 0.95; 95\% CI, 0.91-0.99; $P=.009$ ) and not surgical procedure (HR, $2.76 ; 95 \% \mathrm{CI}, 0.83-9.16 ; P=.099)$, as an independent prognostic factor for OS.

Conclusions: Sublobar resection may be a potential alternative choice for clinical stage I NSCLC with ILD on HRCT. (J Thorac Cardiovasc Surg 2017;154:1089-96)

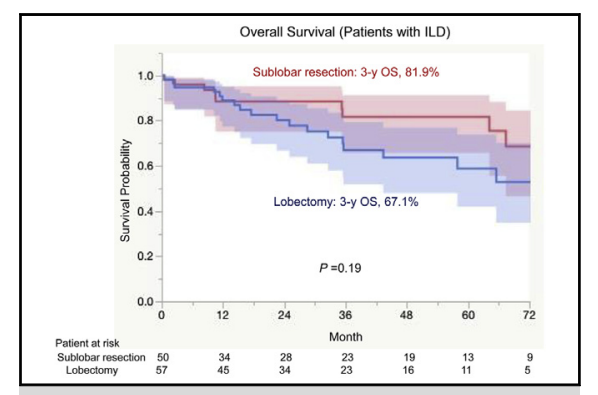

Overall survival in patients with clinical stage I nonsmall cell lung cancer with interstitial lung disease.

\section{Central Message}

Sublobar resection may be a potential alternative to lobectomy for clinical stage I non-small cell lung cancer with interstitial lung disease on high-resolution computed tomography.

\section{Perspective}

Sublobar resection may be a potential alternative choice for clinical stage I non-small cell lung cancer in patients with interstitial lung disease on high-resolution computed tomography, with overall survival comparable with that seen after lobectomy.

See Editorial Commentary page 1097.

See Editorial page 1074.
Interstitial lung disease (ILD), including pulmonary fibrosis, has been reported to be associated with an increased risk of lung cancer. ${ }^{1-3}$ It is reported that $4 \%$ to

\footnotetext{
From the Department of Surgical Oncology, Hiroshima University, Hiroshima, Japan. Received for publication May 4, 2016; revisions received Feb 27, 2017; accepted for publication March 25, 2017; available ahead of print May 5, 2017.

Address for reprints: Morihito Okada, MD, PhD, Department of Surgical Oncology, Research Institute for Radiation Biology and Medicine, Hiroshima University, 1-2-

3-Kasumi, Minami-ku, Hiroshima City, Hiroshima 734-0037, Japan (E-mail: morihito@hiroshima-u.ac.jp).

$0022-5223 / \$ 36.00$

Copyright (c) 2017 by The American Association for Thoracic Surgery

http://dx.doi.org/10.1016/j.jtcvs.2017.03.116
}

$6 \%$ of resected primary lung cancer specimens show evidence of ILD. ${ }^{4,5}$ Although the 30-day mortality rate of patients with lung cancer undergoing lobectomy is as low as $0.3 \%$ in Japan, interstitial pneumonia, which is one of the types of ILD, is the most frequent cause of death after lung cancer surgery. ${ }^{6}$ The incidence and mortality of

Scanning this QR code will take you to supplemental tables, figures, and video for this article. 


\begin{tabular}{|c|c|}
\hline \multicolumn{2}{|c|}{ Abbreviations and Acronyms } \\
\hline ALAT & $\begin{aligned}= & \text { Latin American Thoracic } \\
& \text { Association }\end{aligned}$ \\
\hline ATS & $=$ American Thoracic Society \\
\hline $\mathrm{CI}$ & $=$ confidence interval \\
\hline CSS & $=$ cancer-specific survival \\
\hline $\mathrm{CT}$ & $=$ computed tomography \\
\hline DLCO & $\begin{aligned}= & \text { diffusing capacity of the lung for } \\
& \text { carbon monoxide }\end{aligned}$ \\
\hline ERS & $=$ European Respiratory Society \\
\hline FDG-PE & $\begin{aligned}= & \text { F-18-fluorodeoxyglucose positron } \\
& \text { emission tomography/computed } \\
& \text { tomography }\end{aligned}$ \\
\hline HR & $=$ hazard ratio \\
\hline HRCT & $\begin{aligned}= & \text { high-resolution computed } \\
& \text { tomography }\end{aligned}$ \\
\hline ILD & $=$ interstitial lung disease \\
\hline JRS & $=$ Japanese Respiratory Society \\
\hline NSCLC & $=$ non - small cell lung cancer \\
\hline OS & $=$ overall survival \\
\hline UIP & $=$ usual interstitial pneumonia \\
\hline
\end{tabular}

postoperative acute exacerbations in patients with non- small cell lung cancer (NSCLC) with ILD has been reported to be $0 \%$ to $32 \%$ and $0 \%$ to $23 \%$, respectively. ${ }^{7,8}$ The long-term survival rate of patients with NSCLC with ILD is also poor. In patients with pathologic IA NSCLC with ILD, the 5-year survival rates are reported to range between $54 \%$ and $59 \%,{ }^{5,9}$ whereas the 5 -year survival rate is reported to be $73 \%$ in patients with pathologic IA NSCLC with or without ILD. ${ }^{10}$ Thus, patients with NSCLC with ILD are considered to have worse short- and long-term outcomes after lung resection. Lung cancer is responsible for approximately $50 \%$ of deaths among patients with ILD with lung cancer, with the remaining deaths due to other causes, such as respiratory failure. ${ }^{5,7}$

To improve the outcome of patients with NSCLC and ILD, techniques must simultaneously address the risks of diminished pulmonary function and the risks posted by the cancer. Several studies have demonstrated that the survival rate after sublobar resection is similar to that after standard lobectomy in certain patients with clinical stage IA NSCLC, and sublobar resection has functional advantages over lobectomy. ${ }^{11-15}$ In patients with NSCLC with ILD, sublobar resection may decrease the occurrence of acute exacerbations of ILD. ${ }^{8,16}$ We hypothesized that sublobar resection provides acceptable long-term outcomes and reduces the incidence of postoperative complications compared with lobectomy in patients with NSCLC with ILD. The purpose of the present exploratory study was to investigate the results of sublobar and lobar resection in patients with clinical stage I NSCLC with ILD. Although ILD contains several subtypes such as idiopathic pulmonary fibrosis, nonspecific interstitial pneumonia, sarcoidosis, and others, the prognosis after surgery for NSCLC with each subtype of ILD is not well known. Therefore, we divided ILDs into 3 types based on radiographic findings in this study and compared the outcomes between the procedures stratified by radiographic ILD patterns to explore which patients would benefit from sublobar resection.

\section{PATIENTS AND METHODS \\ Patients}

We included patients with clinical stage I NSCLC from Hiroshima University between April 1, 2007 and December 31, 2015. Patients with multiple tumors, or those who had previously undergone lung surgeries for lung tumors, were excluded from the present study. Patient data were analyzed retrospectively in the present study. High-resolution computed tomography (HRCT) and F-18-fluorodeoxyglucose positron emission tomography/ computed tomography (FDG-PET/CT) followed by surgical resection with curative intent were performed in all patients staged according to the TNM Classification of Malignant Tumors, 7 th Edition. ${ }^{10}$ Neither mediastinoscopy nor endobronchial ultrasonography was performed routinely because all patients underwent preoperative HRCT and FDG-PET/CT. In all patients included in the present study, HRCT and FDG-PET/CT revealed an absence of an enlargement $(<1 \mathrm{~cm})$ in the mediastinal or hilar lymph nodes and an absence of $>1.5$ accumulation for maximum standardized uptake values in the lymph nodes, respectively. Sublobar resection (either wedge resection or segmentectomy) was allowed in patients with complete tumor removal as an optional procedure for peripheral tumors that were assessed intraoperatively as NO by histologic examination of frozen sections of enlarged lymph nodes or by ensuring that there was no obvious lymph node enlargement in the thoracic cavity. Systematic lymph node dissection, ie, of the hilar or mediastinal nodes, was performed during segmentectomy but not during wedge resection (Video 1). Wedge resection was performed for predominantly ground-glass opacity lesions in patients

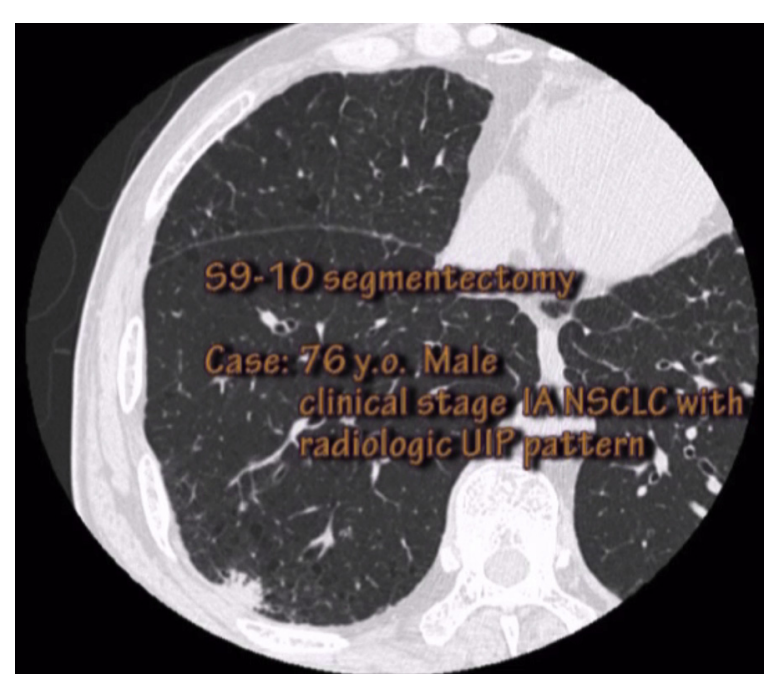

VIDEO 1. Right S9-10 segmentectomy for clinical stage IA non-small cell lung cancer with radiologic usual interstitial pneumonia pattern. UIP, Usual interstitial pneumonia. Video available at: http://www.jtcvsonline. org/article/S0022-5223(17)30635-9/addons. 


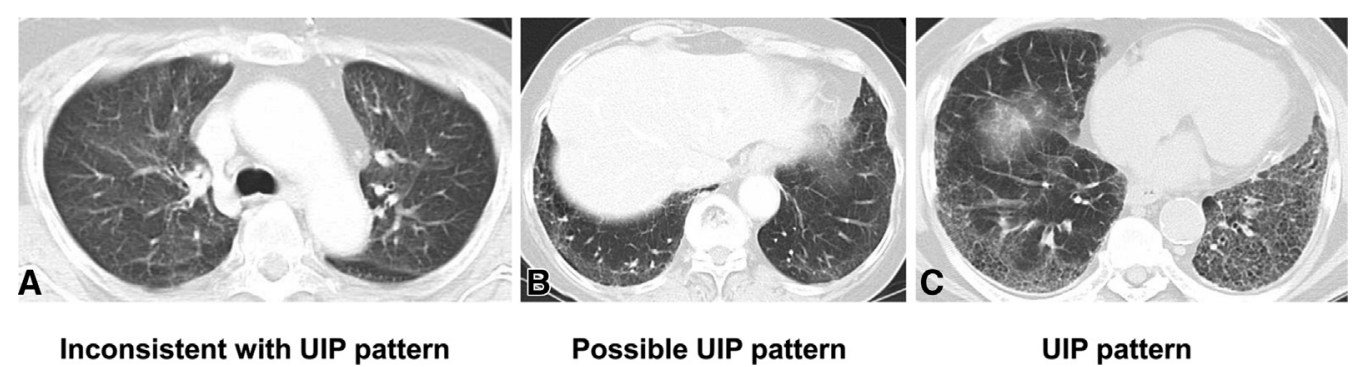

FIGURE 1. Representative interstitial lung disease patterns on computed tomography according to the American Thoracic Society, European Respiratory Society, Japanese Respiratory Society, and Latin American Thoracic Association classifications. A, Findings inconsistent with UIP pattern; upper-lung predominant ground glass abnormality, which is one of the criteria for inconsistent UIP patterns. B, Possible UIP pattern; basal predominant, peripheral predominant reticular abnormality without honeycombing. C, UIP pattern; basal predominant, peripheral predominant reticular abnormality with honeycombing. UIP, Usual interstitial pneumonia.

who were considered unsuitable for lobectomy. We did not usually consider whether the tumor being resected was in an area of radiographic ILD for the choice of surgical procedure.

The inclusion criteria of the present study were as follows: preoperative staging determined using HRCT and FDG-PET/CT; potentially curative surgery without neoadjuvant chemotherapy or radiotherapy; and a definitive histopathologic diagnosis of NSCLC. The present study was approved by the institutional review boards of Hiroshima University. The requirement of obtaining informed consent from individual patients was waived because this study was a retrospective review of a patient database.

\section{High-Resolution Computed Tomography}

Sixteen-row multidetector computed tomography (CT) was used to obtain chest images independently of subsequent FDG-PET/CT examinations. The following parameters were used for high-resolution images of the lung: $120 \mathrm{kVp}$; $200 \mathrm{~mA}$; 1- to 2 -mm section thickness; $512 \times 512$ pixel resolution; 0.5 - to 1.0 -second scanning time; a high-spatial reconstruction algorithm with a 20-cm field of view; and mediastinal (level, $40 \mathrm{HU}$; width, $400 \mathrm{HU}$ ) and lung (level, $-600 \mathrm{HU}$; width, $1600 \mathrm{HU}$ ) window settings. A radiologically determined ILD was defined according to the American Thoracic Society, European Respiratory Society, Japanese Respiratory Society, and Latin American Thoracic Association (ATS/ERS/JRS/ALAT) classifications $^{17}$ as follows:

1. Usual interstitial pneumonia (UIP) pattern (all 4 features): subpleural, basal predominance; reticular abnormality; honeycombing with or without traction bronchiectasis; absence of features listed as inconsistent with UIP pattern.

2. Possible UIP pattern (all 3 features): subpleural, basal predominance; reticular abnormality; absence of features listed as inconsistent with UIP pattern.

3. Inconsistent with UIP pattern (any of the 7 features): upper or mid-lung predominance; peribronchovascular predominance; extensive groundglass abnormality (extent $>$ reticular abnormality); profuse micronodules (bilateral predominantly upper lobes); discrete cysts (multiple, bilateral, away from areas of honeycombing); diffuse mosaic attenuation/air trapping (bilateral, in 3 or more lobes); or consolidation in bronchopulmonary segment(s)/lobe(s).

CT scans were reviewed, and tumor sizes and ILD patterns were determined preoperatively by the tumor board, which included surgical oncologists, medical oncologists, pulmonologists, radiologists, and pathologists.

\section{Follow-up Evaluation}

All patients who underwent lung resection were followed up from the day of surgery. Postoperative complications were defined according to the Clavien-Dindo classification. ${ }^{18}$ The criteria for postoperative acute exacerbation of ILD included any unexplained worsening of dyspnea within 1 month, evidence of hypoxemia, as defined by worsened or severely impaired arterial blood gas exchange more than $10 \mathrm{~mm} \mathrm{Hg}$ under similar conditions, new radiographic alveolar infiltrates, and an absence of an alternative complication, such as infection, pulmonary embolism, pneumothorax, or heart failure. ${ }^{19}$ Postoperative follow-up procedures, including a physical examination, chest roentgenogram every 3 months, and chest and abdominal CT examinations every 6 months, were performed for the first 2 years. Subsequently, a physical examination and chest roentgenogram were performed every 6 months, and a chest CT examination was performed every year.

\section{Statistical Analysis}

The results are presented as numbers $(\%)$ or medians, unless stated otherwise. The $\chi^{2}$ test was used to compare categorical variable frequencies. The Fisher exact test was used for small sample sizes. The overall survival (OS) was defined as the time from the date of surgery until the time of death due to any cause or the last follow-up visit. The Kaplan-Meier method was used to assess OS durations, and these durations were compared with log-rank tests, which were truncated at the 36-month mark. To assess the potential independent effects of the surgical procedure on OS, we used a Cox proportional hazards model. To select variables for multivariable analysis, a backward stepwise method was used. The Statistical Package for the Social Sciences (SPSS; version 20; IBM Corp, Armonk, NY) was used for statistical analysis. The significance level was set at a $P$ value of $<.05$.

\section{RESULTS \\ Comparison of Outcomes Among Radiologic Non- ILD and ILD Patterns}

Overall, 107 of 796 patients had clinical stage I NSCLC with ILD on HRCT. The median follow-up period postoperatively was 37.3 months (0.34-107.7 months). ILDs were divided into 3 groups (UIP, possible UIP, inconsistent with UIP) according to the ATS/ERS/JRS/ALAT classification (Figure 1). Patient characteristics based on ILD patterns are shown in Table 1. Pathologic findings of resected specimens are shown in Table E1. None of the 47 patients $(0 \%)$ with "ILD inconsistent with UIP" on HRCT showed a pathologic UIP pattern. Seven of $33(21.2 \%)$ with "ILD with possible UIP" on HRCT and 18 of $27(66.7 \%)$ with "ILD with UIP" on HRCT showed pathologic UIP patterns in the resected lung tissue. OS was significantly lower in 
TABLE 1. Clinicopathologic features of patients with clinical stage I non-small cell lung cancer with ILD according to the ATS/ERS/JRS/ALAT classification

\begin{tabular}{|c|c|c|c|c|}
\hline Variables & Non-ILD $(n=689)$ & Inconsistent with UIP $(n=47)$ & Possible UIP $(\mathbf{n}=\mathbf{3 3})$ & $\mathbf{U I P}(\mathbf{n}=\mathbf{2 7})$ \\
\hline Age, y & $67(30-89)$ & $74(61-86)$ & $72.5(60-92)$ & $72(58-87)$ \\
\hline \multicolumn{5}{|l|}{ Sex } \\
\hline Male & $385(55.9 \%)$ & $31(66.0 \%)$ & $29(87.9 \%)$ & $24(88.9 \%)$ \\
\hline \multicolumn{5}{|l|}{ Smoking history } \\
\hline Yes & $374(54.3 \%)$ & $28(61.7 \%)$ & $32(97.0 \%)$ & $26(96.3 \%)$ \\
\hline \multicolumn{5}{|l|}{ Clinical T } \\
\hline $\mathrm{T} 1$ & $512(74.3 \%)$ & $35(74.5 \%)$ & $22(66.7 \%)$ & $17(63.0 \%)$ \\
\hline $\mathrm{T} 2$ & $177(25.7 \%)$ & $12(25.5 \%)$ & $11(33.3 \%)$ & $10(37.0 \%)$ \\
\hline$\% \mathrm{VC}$ & $99.4(51.2-147.1)$ & $91(61.4-122.2)$ & $93.7(73.5-119.7)$ & $84.6(42.5-106.7)$ \\
\hline FEV1, \% & $75.1(36.4-100)$ & $72.3(31.6-93.5)$ & $74.7(53.8-90.0)$ & $75.7(62.1-86.1)$ \\
\hline$\% \mathrm{DLCO}$ & $80.8(16-135)$ & $60.0(16-99)$ & $62.5(34-103)$ & $45(21-60)$ \\
\hline Serum KL-6 & $223(72-1269)$ & $282(113-578)$ & $404.5(181-993)$ & $710(256-3115)$ \\
\hline \multicolumn{5}{|l|}{ Histology } \\
\hline Adenocarcinoma & $569(82.6 \%)$ & $34(72.3 \%)$ & $15(45.5 \%)$ & $5(18.5 \%)$ \\
\hline Squamous cell carcinoma & $67(9.7 \%)$ & $10(21.3 \%)$ & $13(39.4 \%)$ & $14(51.9 \%)$ \\
\hline Others & $53(7.7 \%)$ & $3(6.4 \%)$ & $5(15.6 \%)$ & $8(29.7 \%)$ \\
\hline \multicolumn{5}{|l|}{ Procedure } \\
\hline Lobectomy & $400(58.1 \%)$ & $24(51.1 \%)$ & $19(57.6 \%)$ & $14(51.9 \%)$ \\
\hline Segmentectomy & $198(28.7 \%)$ & $13(27.7 \%)$ & $9(27.3 \%)$ & $3(11.1 \%)$ \\
\hline Wedge resection & $91(13.2 \%)$ & $10(21.3 \%)$ & $5(15.6 \%)$ & $10(37.0 \%)$ \\
\hline
\end{tabular}

Values are $\mathrm{n}(\%)$ or median (range). $I L D$, Interstitial lung disease; $U I P$, usual interstitial pneumonia; $V C$, vital capacity; $F E V I$, forced expiratory value in 1 second; $D L C O$, diffusion capacity of the lung for carbon monoxide; $K L-6$, Krebs von den Lungen-6.

patients with ILD than in those with non-ILD (hazard ratio $[\mathrm{HR}], 4.17$; 95\% confidence interval [CI], 2.46-7.06; $P<.001)$. OS was significantly lower in patients with "ILD inconsistent with UIP" pattern (HR, 2.66; 95\% CI,
1.19-5.97; $P=.014)$ or in those with "ILD with possible UIP or UIP" patterns (HR, 2.38; 95\% CI, 1.76-3.21; $P<.001$ ) than in those with non-ILD (Figure 2). Among those with ILD on HRCT evaluation, there was no

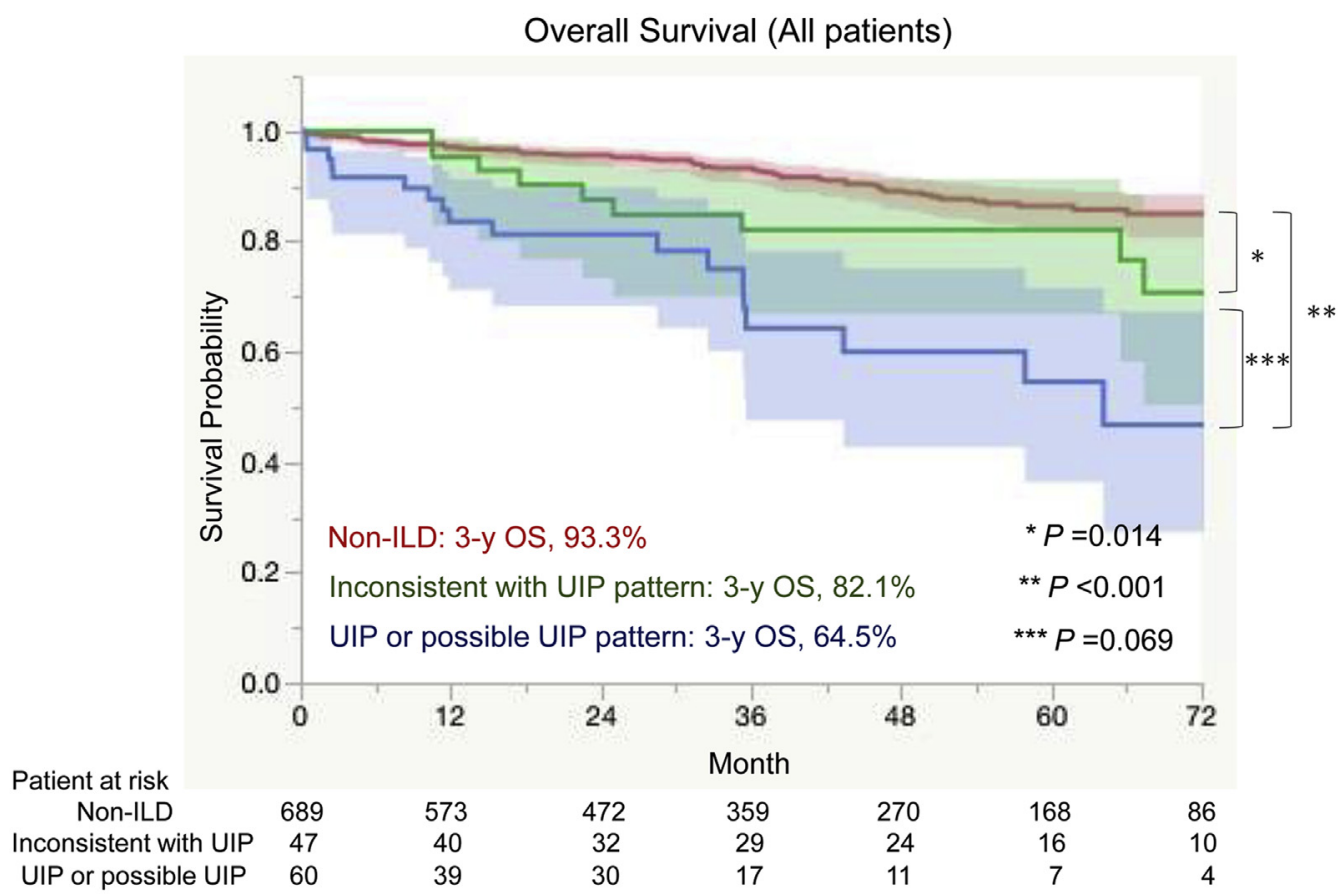

FIGURE 2. OS in patients with clinical stage I non-small cell lung cancer with or without ILD. In all patients, the 3-year OS rates of $93.3 \%, 82.1 \%$, and $64.5 \%$ were observed among patients with non-ILD, inconsistent UIP patterns, and possible UIP or UIP patterns, respectively. OS, Overall survival; ILD, interstitial lung disease; UIP, usual interstitial pneumonia. 
TABLE 2. Comparison of the clinical characteristics between patients who underwent lobectomy and those who underwent sublobar resection

\begin{tabular}{|c|c|c|c|}
\hline Variables & $\begin{array}{c}\text { Lobectomy } \\
(\mathrm{n}=\mathbf{5 7})\end{array}$ & $\begin{array}{c}\text { Sublobar } \\
\text { resection } \\
(\mathbf{n}=\mathbf{5 0})\end{array}$ & $\begin{array}{c}P \\
\text { value }\end{array}$ \\
\hline Age, y & $70.5(58-85)$ & $75(62-92)$ & .14 \\
\hline \multicolumn{4}{|l|}{ Sex } \\
\hline Male & $46(80.7 \%)$ & $38(76.0 \%)$ & .64 \\
\hline \multicolumn{4}{|l|}{ Smoking history } \\
\hline Yes & $48(84.2 \%)$ & $38(76.0 \%)$ & .33 \\
\hline \multicolumn{4}{|l|}{ Clinical T } \\
\hline $\mathrm{T} 1$ & $30(52.6 \%)$ & $44(88.0 \%)$ & $<.001$ \\
\hline $\mathrm{T} 2$ & $27(47.4 \%)$ & $6(12.0 \%)$ & \\
\hline \multicolumn{4}{|l|}{ ILD pattern } \\
\hline Inconsistent with UIP & $24(42.1 \%)$ & $23(46.0 \%)$ & .84 \\
\hline Possible UIP & $19(33.3 \%)$ & $14(28.0 \%)$ & \\
\hline UIP & $14(24.7 \%)$ & $13(26.0 \%)$ & \\
\hline$\% \mathrm{VC}$ & $90.6(54.7-122.2)$ & $92.1(42.5-119.7)$ & .42 \\
\hline FEV1, \% & $73.8(49.0-91.1)$ & $76.2(31.6-93.5)$ & .11 \\
\hline$\%$ DLCO & $59.5(25-99)$ & $50(16-103)$ & .88 \\
\hline Serum KL-6 & $421(161-2639)$ & $393(113-3115)$ & .80 \\
\hline \multicolumn{4}{|l|}{ Histology } \\
\hline Adenocarcinoma & $28(49.1 \%)$ & $26(52.0 \%)$ & .74 \\
\hline Squamous cell carcinoma & $20(35.1 \%)$ & $17(34.0 \%)$ & \\
\hline Others & $9(15.8 \%)$ & $7(14.0 \%)$ & \\
\hline
\end{tabular}

Values are $\mathrm{n}(\%)$ or median (range). ILD, Interstitial lung disease; $U I P$, usual interstitial pneumonia; $V C$, vital capacity; $F E V I$, forced expiratory value in 1 second; $D L C O$, diffusion capacity of the lung for carbon monoxide; $K L-6$, Krebs von den Lungen-6.

significant difference in OS between patients with "ILD inconsistent with UIP" pattern versus those with "ILD with possible UIP or UIP" patterns $(P=.069)$.

\section{Comparison of Outcomes Between Lobectomy and Sublobar Resection in Patients With ILD}

Table 2 shows preoperative clinical factors between patients who underwent lobectomy and those who underwent sublobar resection. Eighteen $(36 \%)$ sublobar resections were intended for patients who were not considered surgically fit to undergo lobectomy. Patient clinical characteristics were comparable between groups, except at the clinical stage. Pathologic stages are shown in Table E2. Operation

TABLE 3. Short-term outcomes after lobectomy or sublobar resection in patients with clinical stage I non-small cell lung cancer with interstitial lung disease

\begin{tabular}{|c|c|c|c|}
\hline Variables & $\begin{array}{c}\text { Lobectomy } \\
(\mathrm{n}=\mathbf{5 7})\end{array}$ & $\begin{array}{c}\text { Sublobar } \\
\text { resection } \\
(\mathbf{n}=\mathbf{5 0})\end{array}$ & $P$ value \\
\hline Operation time, $\min$ & $164(86-387)$ & $126(33-309)$ & .001 \\
\hline $\begin{array}{l}\text { Postoperative acute } \\
\quad \text { exacerbation }(\leq \text { POD } 30)\end{array}$ & $3(5.7 \%)$ & $3(6.0 \%)$ & 1.0 \\
\hline $\begin{array}{l}\text { Postoperative complication } \\
\quad(\geq \text { grade } 3)\end{array}$ & $5(8.8 \%)$ & $1(2.0 \%)$ & .21 \\
\hline 90-d mortality & $3(5.7 \%)$ & $2(4.0 \%)$ & 1.0 \\
\hline
\end{tabular}

$P O D$, Postoperative day. time was significantly longer for lobectomy than for sublobar resection (164 minutes vs 126 minutes, $P=.001$; Table 3). The short-term outcomes were comparable between lobectomy and sublobar resection. The incidences of postoperative acute exacerbation of ILD within 30-day and 90-day postoperative mortality were similar between lobectomy and sublobar resection $(5.7 \%$ vs $6.0 \%$ exacerbation and $5.7 \%$ vs $4.0 \%$ 90-day mortality; $P=1.0$ and $P=1.0$, respectively; Table 3 ). The incidence of grade 3 or greater postoperative complications was greater after lobectomy than that after sublobar resection; however, this difference was not statistically significant $(8.8 \%$ vs $2.0 \%$, $P=.21$; Table 3).

Among patients with ILD, no significant difference in OS was observed between lobectomy and sublobar resection $(P=.19$; Figure $3, A)$. In patients with clinical stage IA NSCLC and ILD, no statistically significant difference in OS was observed between lobectomy and sublobar resection $(P=.87$; Figure $3, B)$. In patients with "ILD inconsistent with UIP" pattern, OS was similar between lobectomy and sublobar resection $(P=.91$; Figure $3, C)$. In patients with "ILD with possible UIP" or "ILD with UIP" patterns, OS was greater after sublobar resection than after lobectomy; however, this difference was not statistically significant $(P=.11$; Figure $3, D)$. Cox proportional hazard models including operative procedure, age, sex, clinical stage, ILD pattern, percent vital capacity, forced expiratory value in 1 second, and percent diffusing capacity of the lung for carbon monoxide ( $\% \mathrm{DLCO})$ demonstrated that the $\%$ DLCO was an independent prognostic factor for OS (HR, 0.95; 95\% CI, 0.91-0.99; $P=.009$; Table 4).

Cancer-specific survival was not significantly different between patients who underwent lobectomy and those who underwent sublobar resection $(P=.88$; Figure E1). Death occurred in 18 of 57 patients who underwent lobectomy (6 from lung cancer, 8 from respiratory failure, and 4 from other causes) and 9 of 50 patients who underwent sublobar resection ( 3 from lung cancer, 5 from respiratory failure, and 1 from other cause).

\section{DISCUSSION}

The present study aimed to explore the outcomes of sublobar resection and lobectomy for patients with early NSCLC with ILD. OS was not statistically different between lobectomy and sublobar resection in patients with clinical stage I NSCLC with ILD, even when stratified by radiographic ILD patterns. Radiologic ILD patterns defined according to the ATS/ERS/JRS/ALAT classification were consistent with the incidence of pathologically proven UIP patterns in the present study. However, $35.5 \%$ of patients with radiographic ILD did not have the evidence of ILD pathologically. One of the possible reasons for the discrepancy is that the resected specimens did not always include the radiographic ILD lesions. 

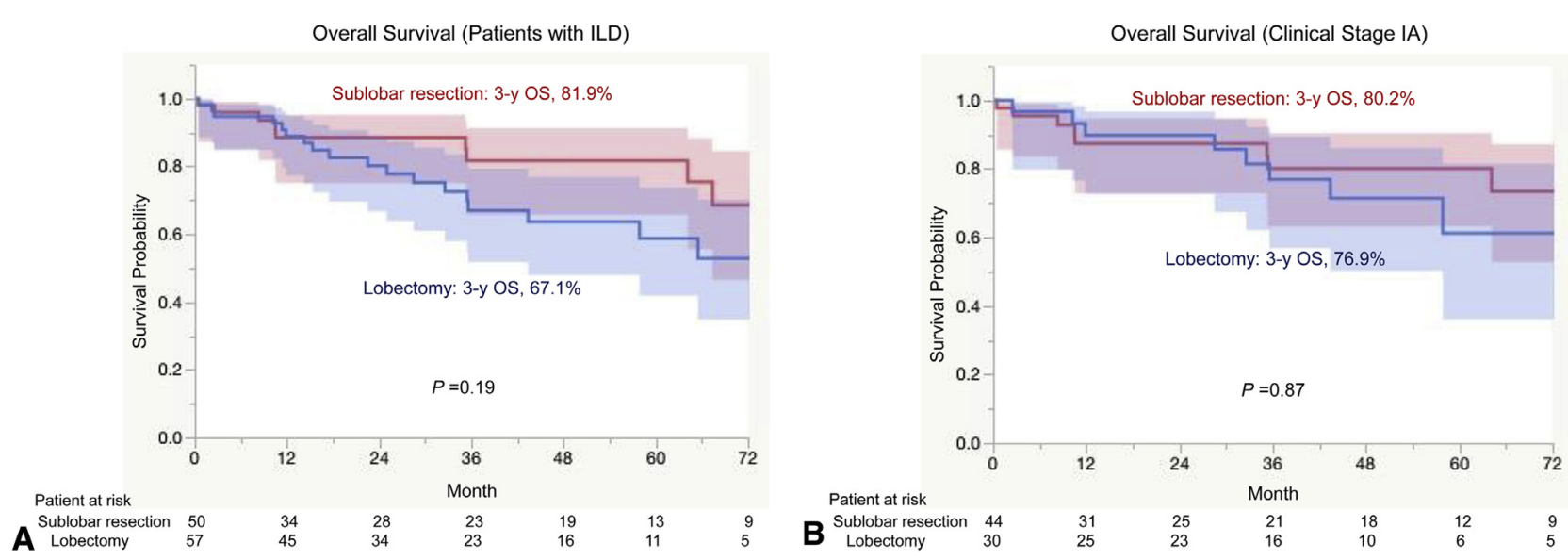

Overall Survival (Inconsistent with UIP pattern)

B Lobectom

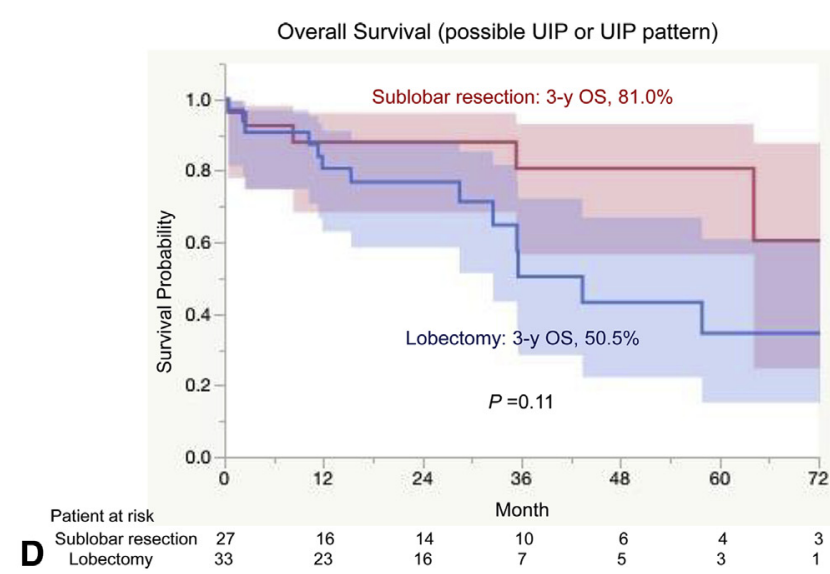

$\begin{array}{llllllll}\text { C Sublobar resection } & 23 & 18 & 14 & 13 & 13 & 9 & 7 \\ \text { Lobectomy } & 24 & 22 & 18 & 16 & 11 & 7 & 4\end{array}$

FIGURE 3. OS between lobectomy and sublobar resection in patients with clinical stage I NSCLC and ILD. A, In all patients, the 3-year OS rates of 67.1\% and $81.9 \%$ were observed between patients who underwent lobectomy and those who underwent sublobar resection, respectively $(P=.19)$. B, In patients with clinical stage IA NSCLC with ILD, the 3-year OS rates of $76.9 \%$ and $80.2 \%$ were observed between patients who underwent lobectomy and those who underwent sublobar resection, respectively $(P=.87)$. C, In patients with inconsistent UIP pattern, the 3-year OS rates of $81.1 \%$ and $83.6 \%$ were observed between patients who underwent lobectomy and those who underwent sublobar resection, respectively $(P=.91)$. D, In patients with possible UIP or UIP pattern, the 3 -year OS rates of $50.5 \%$ and $81.0 \%$ were observed between patients who underwent lobectomy and those who underwent sublobar resection, respectively $(P=.11)$. ILD, Interstitial lung disease; $O S$, overall survival; UIP, usual interstitial pneumonia.

The surgical outcomes were compared between lobectomy and sublobar resection in the current study. Although the incidence of postoperative acute exacerbation and 90day mortality was similar between the procedures, severe postoperative complications were less common in the sublobar resection group compared with those in the lobectomy group; however, this difference was not statistically significant but could be clinically important. Several studies have reported that sublobar resection reduces the incidence of postoperative acute exacerbation of ILD, postoperative complications, and short-term mortality in patients with lung cancer with or without ILD., ${ }^{4,6,16}$ Our results partially corroborate those of previous studies, indicating that sublobar resection may have an advantage in terms of short-term outcomes in patients with NSCLC with ILD.

Although no significant difference in OS was observed between lobectomy and sublobar resection in patients with clinical stage I NSCLC and ILD, 3-year OS was better for sublobar resection $(81.9 \%)$ than lobectomy $(67.1 \%)$. A larger number of patients and longer follow-up will be needed for a more definitive prospective study. In the exploratory subgroup analyses, OS was similar between procedures in patients with "ILD inconsistent with UIP" patterns, whereas OS was better after sublobar resection without statistically significant difference in patients with "ILD with possible UIP or UIP" patterns. A previous multi-institutional retrospective study reported that wedge resection resulted in worse long-term survival than lobectomy in patients with stage IA NSCLC and ILD. ${ }^{5}$ However, the same study reported the prognosis by pathologic stage including wedge resection without lymph node dissection, which may result in stage migration and explain the apparent inconsistency in the results of our study. When comparing the outcomes between operative procedures in retrospective studies, preoperative factors should be used because the choice of the surgical procedure is not 
TABLE 4. Uni- and multivariable Cox proportional hazard model for overall survival in patients with clinical stage I non-small cell lung cancer with ILD

\begin{tabular}{|c|c|c|c|c|}
\hline \multirow[b]{2}{*}{ Variables } & \multicolumn{2}{|c|}{ Univariable } & \multicolumn{2}{|c|}{ Multivariable } \\
\hline & Hazard ratio $(95 \%$ CI $)$ & $P$ value & Hazard ratio $(95 \% \mathrm{CI})$ & $P$ value \\
\hline \multicolumn{5}{|l|}{ Procedure } \\
\hline Lobectomy (vs sublobar resection) & $1.82(0.81-4.06)$ & .15 & $2.76(0.83-9.16)$ & .099 \\
\hline Age & $1.05(0.99-1.11)$ & .12 & & \\
\hline \multicolumn{5}{|l|}{ Sex } \\
\hline Female (vs male) & $0.74(0.28-1.94)$ & .54 & & \\
\hline \multicolumn{5}{|l|}{ Clinical T } \\
\hline $\mathrm{T} 2$ (vs T1) & $2.12(0.98-4.59)$ & .057 & & \\
\hline \multicolumn{5}{|l|}{ ILD pattern } \\
\hline UIP or possible UIP (vs inconsistent with UIP) & $2.42(1.07-5.44)$ & .033 & $3.79(0.97-14.8)$ & .055 \\
\hline$\% \mathrm{VC}^{*}$ & $0.97(0.95-0.99)$ & .007 & & \\
\hline FEV1, \%* & $1.01(0.98-1.05)$ & .52 & & \\
\hline$\% \mathrm{DLCO} *$ & $0.97(0.94-1.00)$ & .035 & $0.95(0.91-0.99)$ & .009 \\
\hline
\end{tabular}

$C I$, Confidence interval; $I L D$, interstitial lung disease; $U I P$, usual interstitial pneumonia; $V C$, vital capacity; $F E V I$, forced expiratory value in 1 second; $D L C O$, diffusion capacity of the lung for carbon monoxide. *Continuous variables.

determined by postoperative factors. Although we compared the procedure in a preoperative setting, it was not possible to avoid selection bias because of the retrospective nature of the present study.

Because sublobar resections were performed predominantly for smaller tumors in the present study, we performed a subanalysis to compare the prognosis of clinical stage IA NSCLC between the procedures, which revealed that OS was similar between patients who underwent lobectomy and those who underwent sublobar resection. In addition, we used multivariable Cox analysis to adjust for potential bias and demonstrated that only \%DLCO was an independent prognostic factor for OS and not the surgical procedure. Previous studies have reported that \%DLCO is associated with long-term survival after lung resection for lung cancer. ${ }^{20-22}$ Our result is consistent with these previous studies and indicates the preservation of DLCO may be important, particularly in patients with NSCLC with ILD, who generally have poor pulmonary function compared with patients without ILD. These patients may be potential candidates for sublobar resection despite being fit for lobectomy. When we focused on the oncologic effect of sublobar resection, cancer-specific survival was similar between the procedures.

The present study has some limitations. This was a single-institution retrospective study, and patients who underwent sublobar resection may be highly selected. The potential selection bias should be taken into account to evaluate the short-term or long-term results in this study. One half of the sublobar resections reported here were wedge resections without nodal dissection. The difference in outcomes between segmentectomy and wedge resection should be examined prospectively in the future. Relatively short follow-up period and small numbers of patients in this study may substantially impact the study power. Therefore, longer follow-up is needed to conclude the long-term results.
In conclusion, sublobar resection for clinical stage I NSCLC with ILD seems to be feasible with acceptable short- and long-term outcomes compared with lobectomy, suggesting that sublobar resection may be a potential alternative surgical procedure. The findings of the present study warrant further prospective studies that compare lobectomy and sublobar resection for clinical stage I NSCLC with ILD.

\section{Conflict of Interest Statement}

Authors have nothing to disclose with regard to commercial support.

\section{References}

1. Hubbard R, Venn A, Lewis S, Britton J. Lung cancer and cryptogenic fibrosing alveolitis. A population-based cohort study. Am J Respir Crit Care Med. 2000; 161:5-8.

2. Park J, Kim DS, Shim TS, Lim CM, Koh Y, Lee SD, et al. Lung cancer in patients with idiopathic pulmonary fibrosis. Eur Respir J. 2001;17:1216-9.

3. Turner-Warwick M, Lebowitz M, Burrows B, Johnson A. Cryptogenic fibrosing alveolitis and lung cancer. Thorax. 1980;35:496-9.

4. Committee for Scientific Affairs, Sakata R, Fujii Y, Kuwano H. Thoracic and cardiovascular surgery in Japan during 2009: annual report by the Japanese Association for Thoracic Surgery. Gen Thorac Cardiovasc Surg. 2011;59:636-67.

5. Sato T, Watanabe A, Kondo H, Kanzaki M, Okubo K, Yokoi K, et al. Long-term results and predictors of survival after surgical resection of patients with lung cancer and interstitial lung disease. J Thorac Cardiovasc Surg. 2015;149:64-9.

6. Amano J, Kuwano H, Yokomise H. Thoracic and cardiovascular surgery in Japan during 2011. Annual report by the Japanese Association for Thoracic Surgery. Gen Thorac Cardiovasc Surg. 2013;61:578-607.

7. Watanabe A, Miyajima M, Mishina T, Nakazawa J, Harada R, Kawaharada N, et al. Surgical treatment for primary lung cancer combined with idiopathic pulmonary fibrosis. Gen Thorac Cardiovasc Surg. 2013;61:254-61.

8. Sato T, Teramukai S, Kondo H, Watanabe A, Ebina M, Kishi K, et al. Impact and predictors of acute exacerbation of interstitial lung diseases after pulmonary resection for lung cancer. J Thorac Cadiovasc Surg. 2014;147:1604-11.

9. Saito Y, Kawai Y, Takahashi N, Ikeya T, Murai K, Kawabata Y, et al. Survival after surgery for pathologic stage IA non-small cell lung cancer associated with idiopathic pulmonary fibrosis. Ann Thorac Surg. 2011;92:1812-7.

10. Goldstraw P, Crowley J, Chansky K, Giroux DJ, Groome PA, Rami-Porta R, et al International Association for the Study of Lung Cancer International Staging Committee; Participating Institutions. The IASLC Lung Cancer Staging Project: proposals for the revision of the TNM stage groupings in the forthcoming (seventh) edition of the TNM Classification of Malignant Tumours. J Thorac Oncol. 2007;2:706-14. 
11. Okada M, Koike T, Higashiyama M, Yamato Y, Kodama K, Tsubota N. Radical sublobar resectin for small-sized non-small cell lung cancer: a multicenter study. J Thorac Cardiovasc Surg. 2006;132:769-75.

12. Tsutani Y, Miyata Y, Nakayama H, Okumura S, Adachi S, Yoshimura M, et al. Oncologic outcomes of segmentectomy compared with lobectomy for clinical stage IA lung adenocarcinoma: propensity score-matched analysis in a multicenter study. J Thorac Cardiovasc Surg. 2013;146:358-64.

13. Tsutani Y, Miyata Y, Nakayama H, Okumura S, Adachi S, Yoshimura M, et al. Appropriate sublobar resection choice for ground glass opacity-dominant clinical stage IA lung adenocarcinoma: wedge resection or segmentectomy. Chest. 2014; 145:66-71.

14. Landreneau RJ, Normolle DP, Christie NA, Awais O, Wizorek JJ, Abbas G, et al Recurrence and survival outcomes after anatomic segmentectomy versus lobectomy for clinical stage I non-small-cell lung cancer: a propensity-matched analysis. J Clin Oncol. 2014;32:2449-55.

15. Tsutani Y, Miyata Y, Nakayama H, Okumura S, Adachi S, Yoshimura M, et al. Sublobar resection for lung adenocarcinoma meeting node-negative criteria on preoperative imaging. Ann Thorac Surg. 2014;97:1701-7.

16. Yano M, Sasaki H, Moriyama S, Hikosaka Y, Yokota K, Kobayashi S, et al. Postoperative acute exacerbation of pulmonary fibrosis in lung cancer patients undergoing lung resection. Interact Cardiovasc Thorac Surg. 2012;14:146-50.

17. Raghu G, Collard HR, Egan JJ, Martinez FJ, Behr J, Brown KK, et al. An official ATS/ERS/JRS/ALAT statement: idiopathic pulmonary fibrosis: evidence-based guidelines for diagnosis and management. Am J Respir Crit Care Med. 2011; 183:788-824.

18. Clavien PA, Barkun J, de Oliveira ML, Vauthey JN, Dindo D, Schulick RD, et al. The Clavien-Dindo classification of surgical complications; five-year experience. Ann Surg. 2009;250:187-96.

19. Collard HR, Moore BB, Flaherty KR, Brown KK, Kaner RJ, King TE Jr, et al. Acute exacerbations of idiopathic pulmonary fibrosis. Am J Respir Crit Care Med. 2007;176:636-43.

20. Ferguson MK, Dignam JJ, Siiddique J, Vigneswaran WT, Celauro AD. Diffusing capacity predicts long-term survival after lung resection for cancer. Eur J Cardiovasc Surg. 2012;41:e81-6.

21. Ferguson MK, Watson S, Johnson E, Vigneswaran WT. Predicted postoperative lung function is associated with all-cause long-term mortality after major lung resection for cancer. Eur J Cardiovasc Surg. 2014;45:660-4.

22. Berry MF, Jeffrey Yang CF, Hartwig MG, Tong BC, Harpole DH, D’Amico TA, et al. Impact of pulmonary function measurements on long-term survival after lobectomy for stage I non-small cell lung cancer. Ann Thorac Surg. 2015;100: 271-6.

Key Words: interstitial lung disease, interstitial pneumonia, lobectomy, non-small cell lung cancer, segmentectomy, sublobar resection, wedge resection 


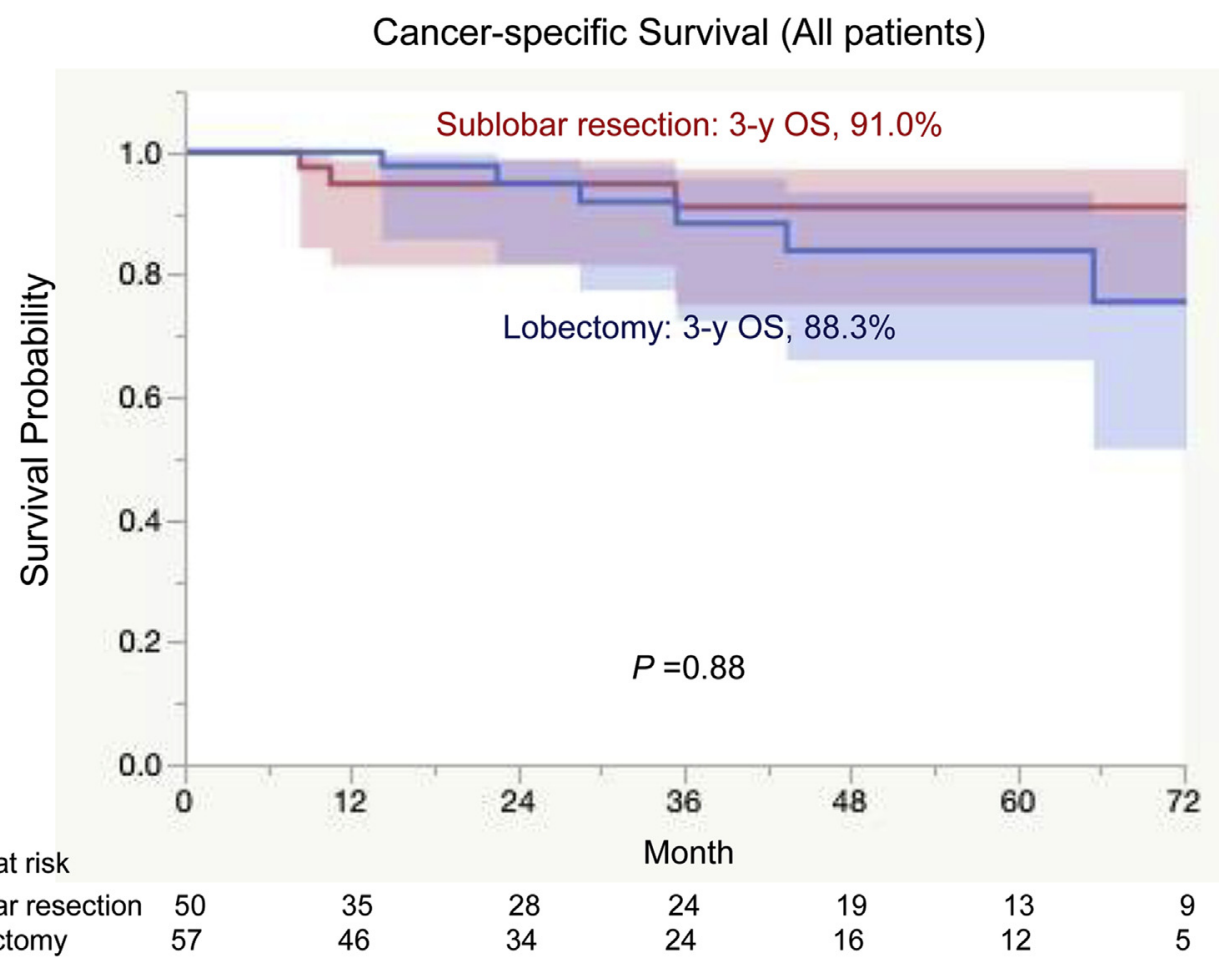

FIGURE E1. Comparison of CSS between lobectomy and sublobar resection in patients with clinical stage I non-small cell lung cancer and interstitial lung disease. The 3-year CSS rates of $88.3 \%$ and $91.0 \%$ were observed between patients who underwent lobectomy and those who underwent sublobar resection, respectively $(P=.88)$. OS, Overall survival.

TABLE E1. Pathologic findings of resected specimens

\begin{tabular}{|c|c|c|c|c|}
\hline Variables & Total $(\mathbf{n}=107)$ & $\begin{array}{l}\text { Inconsistent with UIP } \\
(\mathrm{n}=47)\end{array}$ & Possible UIP $(n=33)$ & $\mathbf{U I P}(n=27)$ \\
\hline UIP & $25(23.4)$ & $0(0)$ & $7(21.2)$ & $18(66.7)$ \\
\hline Subpleural fibrosis & $14(13.1)$ & $4(8.5)$ & $8(24.2)$ & $2(7.4)$ \\
\hline Organizing pneumonia & $6(5.6)$ & $4(8.5)$ & $2(6.1)$ & $0(0)$ \\
\hline Granulomatosis & $4(3.7)$ & $1(2.1)$ & $1(3.0)$ & $2(7.4)$ \\
\hline Asbestosis & $1(0.9)$ & $0(0)$ & $0(0)$ & $1(3.7)$ \\
\hline Eosinophilic pneumonia & $1(0.9)$ & $0(0)$ & $0(0)$ & $1(3.7)$ \\
\hline Hemorrhage & $1(0.9)$ & $1(2.1)$ & $0(0)$ & $0(0)$ \\
\hline Emphysema & $16(15.0)$ & $7(14.9)$ & $8(24.2)$ & $1(3.7)$ \\
\hline Multifocal AAH & $1(0.9)$ & $1(2.1)$ & $0(0)$ & $0(0)$ \\
\hline No evidence of disease & $38(35.5)$ & $29(61.7)$ & $7(21.2)$ & $2(7.4)$ \\
\hline
\end{tabular}

Values are n (\%). UIP, Usual interstitial pneumonia; $A A H$, atypical adenomatous hyperplasia.

TABLE E2. Pathologic stages between lobectomy and sublobar resection

\begin{tabular}{lcc}
\hline Pathologic stage & Lobectomy $(\mathbf{n}=\mathbf{5 7})$ & Sublobar resection $(\mathbf{n}=\mathbf{5 0})$ \\
\hline IA & $20(35.1)$ & $18(36.0)$ \\
IB & $22(38.6)$ & $6(12.0)$ \\
IIA & $5(8.8)$ & $0(0)$ \\
IIB & $4(7.0)$ & $0(0)$ \\
IIIA & $5(8.8)$ & $1(2.0)$ \\
IIIB & $1(1.8)$ & $0(0)$ \\
$X^{*}$ & $0(0)$ & $25(50.0)$ \\
\hline
\end{tabular}

Values are $\mathrm{n}(\%)$. *Cases of wedge resection; due to no lymph node dissection/sampling. 